\title{
AVALIAÇÕES EXTERNAS: TENSÕES E DESAFIOS PARA A GESTĨO ESCOLAR
}

\author{
CYNTHIA PAES DE CARVALHO \\ ANA CRISTINA PRADO DE OLIVEIRA \\ MARIA DE FÁTIMA MAGALHÃES DE LIMA
}

\section{RESUMO}

No contexto das políticas de avaliação e responsabilização na rede pública municipal de ensino do Rio de Janeiro, o artigo traz três estudos que partem de observações e entrevistas realizadas em uma escola pública da rede e de incursões exploratórias sobre os dados dos questionários contextuais dos diretores da Prova Brasil 2007, 2009 e 2011. São discutidos os desafios e as tensões cada vez mais presentes na pauta da gestão escolar, com destaque para a sobrecarga de trabalho burocrático num contexto de precariedade de condições de administração, de uma mediação tensa das políticas junto aos agentes escolares e ainda das tendências de mudanças na gestão pedagógica. Conclui-se ressaltando a importância do adensamento da reflexão sobre a pesquisa e a formação em gestão escolar diante dos novos desafios políticos e pedagógicos, sem perder de vista suas limitações administrativas e político-legais.

PALAVRAS-CHAVE GESTÃO ESCOLAR • AVALIAÇÃO DA EDUCAÇÃO • RESPONSABILIZAÇÃO • RIO DE JANEIRO. 


\section{RESUMEN}

En el marco de las políticas de evaluación y responsabilización en la red pública municipal de enseñanza de Rio de Janeiro, el artículo presenta tres estudios que parten de observaciones $y$ entrevistas realizadas en una escuela pública de la red y de incursiones exploratorias de los datos de los cuestionarios contextuales de los directores de la Prova Brasil 2007, 2009 y 2011. Se discuten los desafíos y tensiones crecientemente presentes en la pauta de la gestión escolar, con destaque para la sobrecarga de trabajo burocrático en un contexto de precariedad de condiciones de administración, una mediación tensa de las políticas junto a los agentes escolares y asimismo las tendencias de cambios en la gestión pedagógica. Se concluye resaltando la importancia del incremento de la reflexión sobre la investigación y la formación en gestión escolar frente a los nuevos desafíos políticos y pedagógicos, sin perder de vista sus limitaciones administrativas y político-legales.

PALABRAS CLAVE GESTIÓN ESCOLAR - EVALUACIÓN DE LA EDUCACIÓN • RESPONSABILIZACIÓN・RIO DE JANEIRO.

\section{ABSTRACT}

In the context of evaluation and accountability policies in the public municipal school network in Rio de Janeiro, this article deals with three studies based on observations and interviews conducted in one public school in the network and exploratory inroads about the data from the contextual questionnaires of the directors of the 2007, 2009 and 2011 Prova Brasil. The increasing challenges and tensions present in the agenda of school management are discussed, highlighting the bureaucratic work overload in a context of the precarious conditions of administration, of a tense mediation of the policies together with the school agents and, also, the trends of changes in school management. It concludes by highlighting the importance of the consolidation of thinking about research, and the preparation of school management in the face of the new political and pedagogical changes, without losing sight of their administrative and politico-legal limitations.

KEYWORDS EDUCATIONAL MANAGEMENT • EDUCATIONAL EVALUATION • ACCOUNTABILITY • RIO DE JANEIRO. 


\section{INTRODUÇÃO}

Propõe-se, neste artigo, a discussão sobre as demandas da gestão escolar frente às estratégias de avaliação externa e às políticas de responsabilização adotadas em alguns segmentos - estaduais e/ou municipais - da educação pública brasileira. $O$ texto encontra-se organizado em seis seções, incluindo esta introdução. O contexto dessa análise - tratado na segunda seção deste artigo - é a introdução de sistemas de avaliação externa para aferição da aprendizagem nas escolas brasileiras, que se inicia na década de 1990. As mudanças na rotina escolar, trazidas pela introdução dessas políticas, estabelecem demandas específicas para o trabalho da gestão da escola.

A terceira seção trata da centralidade da gestão para a eficácia escolar e dos impactos percebidos no trabalho da direção e da coordenação de uma escola municipal do Rio de Janeiro, campo de um estudo de caso nos anos 2010 e 2011 (OLIVEIRA, 2012a). Entre os resultados desse estudo, destacam-se as preocupações da equipe de gestão com as metas de desempenho que a escola devia alcançar, já que a 
equipe tinha que lidar com desafios que comprometiam suas condições de trabalho, como a ausência de funcionários ou docentes.

Na quarta seção, essa problemática é analisada com base em um levantamento de dados provenientes das edições de 2007, 2009 e 2011 da Prova Brasil. Nesse segundo movimento de pesquisa, são estabelecidas algumas comparações com o objetivo de examinar as possíveis mudanças nas estratégias adotadas por gestores escolares a partir da premiação (ou não premiação) recebida em reconhecimento pelo fato de a referida escola ter atingido a meta estabelecida pela Secretaria Municipal de Educação do Rio de Janeiro (SME/RJ). Os resultados desse estudo exploratório são apresentados na quinta seção do artigo, seguidos de uma exposição das características das políticas de responsabilização.

Finalmente, a sexta seção traz uma análise do cenário em que se desenvolveram os três estudos, propondo uma reflexão sobre o papel da gestão escolar em um contexto de avaliações externas e políticas de responsabilização.

\section{POLÍTICAS DE AVALIAÇÃO E RESPONSABILIZAÇÃO}

No Brasil, desde 1990, o Sistema de Avaliação da Educação Básica (Saeb) tornou possível conhecer - com base na aplicação de avaliações externas a amostras representativas por unidades da federação - o desempenho dos alunos em Língua Portuguesa e Matemática em cada segmento do ensino fundamental e no ensino médio. Em 2005, o Ministério da Educação (MEC) ampliou o monitoramento do ensino fundamental por meio da Prova Brasil, que avalia o desempenho em Língua Portuguesa e Matemática dos alunos dos anos finais de cada segmento dessa etapa de ensino ( $5^{\circ}$ e $9^{\circ}$ anos) em todas as escolas da rede pública do país com mais de 20 estudantes matriculados nos anos avaliados. Sua intenção diagnóstica é defendida pelo Plano de Metas Todos pela Educação:

Com os resultados do Prova Brasil, as secretarias e o MEC têm um diagnóstico da Educação brasileira, podendo detectar desigualdades nas escolas e entre elas. A partir disso, 
esses órgãos devem definir ações e direcionar recursos para corrigir essas distorções e melhorar a qualidade do ensino. (BRASIL, 2007)

Esse movimento de focalização das políticas federais de avaliação, ocorrido a partir de 2007, tem enfatizado os resultados por escolas e redes de ensino e catalisado ou induzido à adoção de políticas locais (estaduais e municipais) que, em muitos casos, se associam a políticas de responsabilização. Pesquisas recentes de Brooke (2008) e do Grupo de Avaliação e Medidas Educacionais - Game - da Faculdade de Educação da Universidade Federal de Minas Gerais - UFMG (2011) registram o crescimento de sistemas subnacionais de avaliação, intensificado nos últimos dez anos, após a aplicação bianual de exames padronizados censitários (Prova Brasil) iniciada em 2005.

Um dos principais fatores que contribuíram para a expansão de sistemas de avaliação foi a criação do Índice de Desenvolvimento da Educação Básica (Ideb) e sua centralidade na política educacional. Por meio desse índice, inscrito no Plano de Desenvolvimento da Educação (PDE), de 2007, foi possível arbitrar e fixar metas bianuais por escola e rede de ensino. O Ideb - descrito por Fernandes e Gremaud (2009, p. 1) como "um indicador sintético da qualidade da educação básica, que considera tanto o desempenho dos estudantes em exames padronizados quanto a progressão desses alunos no sistema" - combina o fluxo escolar (taxas de reprovação e aprovação) com o resultado do desempenho padronizado na Prova Brasil, monitora as ações do PDE e é divulgado a cada dois anos, com acesso público no portal do MEC e do Instituto Nacional de Estudos e Pesquisas Educacionais Anísio Teixeira (Inep). Cabe sublinhar, também, a importância estratégica do "Plano de Metas Compromisso Todos Pela Educação" como instrumento que provocou a assunção de uma responsabilidade pactuada e propiciou uma relação de colaboração mais sistemática entre a União, os estados e os municípios, condicionando o apoio técnico e as transferências voluntárias do MEC à adesão ao PDE e ao consequente alcance das 28 diretrizes nele estabelecidas. O Plano obteve a adesão de 
100\% dos municípios e vincula o aporte técnico e financeiro à elaboração dos Planos de Ações Articuladas, que deve ocorrer com a participação dos gestores, da sociedade civil e dos educadores locais.

É importante ressaltar que, por meio da divulgação de resultados e da fixação de metas, o MEC pôde estabelecer uma forma branda de accountability, na qual estados e municípios passaram a monitorar a qualidade do ensino, prestar informações sobre os resultados de desempenho e intermediar apoio técnico e financeiro para as escolas que apresentam piores resultados.

Dessa maneira, percebe-se que o uso dos resultados das avaliações de exames padronizados articulados à política de responsabilização, com consequências fortes para as escolas brasileiras, não foi preconizado por um sistema central de avaliação no Brasil. Na verdade, pode-se levantar a hipótese de que o desenho de política, com base nos dados das avaliações externas, está mais estreitamente relacionado à autonomia das redes públicas de ensino na gestão de seus sistemas, ao funcionamento descentralizado do federalismo brasileiro e às responsabilidades dos estados e municípios pela qualidade do ensino médio e fundamental, conforme inscrito na Constituição Federal de 1988 e na Lei de Diretrizes e Bases de 1996. Adicionalmente, o Ideb tem induzido o desenvolvimento de sistemas de avaliação, planos de metas e políticas de responsabilização com o intuito de melhorar o desempenho acadêmico dos alunos. Esses aspectos são importantes para compreender o contexto favorável ao desenvolvimento de formas de accountability nas redes públicas de ensino brasileiras.

As chamadas "políticas de responsabilização" adotadas em alguns sistemas educacionais estaduais ou municipais comumente oferecem um bônus ou prêmio para aquelas escolas que atingirem as metas estabelecidas para suas unidades de ensino a cada divulgação do Ideb. Algumas características dessas políticas são tributárias das políticas de accountability dos Estados Unidos e foram incorporadas logo no início das políticas de responsabilização no Brasil. Segundo Andrade (2008), a partir de 2006, as políticas nacionais passam a uti- 
1 Segundo o Centro de Seleção e de Promoção de Eventos (CESPE) - da Universidade de Brasília (UnB) responsável pela elaboração $e$ aplicação da Prova Rio, ela é um sistema de avaliação da rede municipal de ensino do Rio de Janeiro e configura-se como uma avaliação longitudinal de desempenho. A Prova é aplicada aos estudantes do $3^{\circ}, 4^{\circ}, 7^{\circ}$ e $8^{\circ}$ anos do ensino fundamental desde 2010. A avaliação do $5^{\circ}$ e do $9^{\circ}$ anos é realizada por meio da Prova Brasil, cuja matriz de referência é compatibilizada para a elaboração das questões da Prova Rio. Seu resultado gera o Índice de Desenvolvimento da Educação do Município do Rio de Janeiro (IDE-Rio) no ano subsequente à aplicação. Esse índice e o Ideb (medido pela Prova Brasil e pela taxa de aprovação) servem como parâmetros para o estabelecimento de bonificações anuais às escolas da rede, conforme 0 Acordo de Resultados - anos ímpares IDE-Rio e anos pares Ideb. Disponível em: <http://provario.cespe.unb.br/ login/index.php> e <http://www cespe.unb.br/noticiashtml/LerNoticia asp?ldNoticia $=752>$. Acesso em 22 jan. 2014 lizar, além da avaliação em larga escala, outra característica da política de school accountability: a divulgação dos resultados por escola. De acordo com o autor, as políticas educacionais locais não haviam incorporado, até aquele momento, dois outros pontos característicos da school accountability, os que se referem ao foco na melhoria do desempenho do aluno e à responsabilização. Até então, em nível nacional, "pode-se dizer que o governo federal adotou uma política branda de school accountability" (ANDRADE, 2008, p. 446).

Dentre as iniciativas localizadas de avaliação do ensino público, destacam-se as experimentadas em Minas Gerais, São Paulo e Rio de Janeiro, oriundas de políticas dos governos desses estados ou de alguns de seus municípios. A intenção dessas iniciativas, em geral, é monitorar o ensino em suas unidades (escolas) a fim de garantir que os alunos estejam sendo efetivamente preparados para a participação na Prova Brasil. Além desse monitoramento, visam também diminuir o índice de reprovação, corrigindo distorções no fluxo dos alunos e garantindo a adequação idade/série. A melhora no resultado da Prova Brasil e no fluxo dos alunos da escola resultaria na elevação do Ideb, meta perseguida pelas secretarias de educação municipais e estaduais. Algumas dessas iniciativas são acompanhadas por estratégias de responsabilização, como o pagamento de recompensa aos professores das escolas que atingem ou ultrapassam as metas estipuladas.

No município do Rio de Janeiro, no qual as pesquisas ora apresentadas foram realizadas, a Secretaria Municipal de Educação desenvolveu, a partir de 2009, uma nova política educacional em consonância com a política nacional, à qual se integrou também uma política de responsabilização, que será descrita detalhadamente na quinta seção. Nessa seção, também serão apresentados os aspectos da política que dizem respeito ao novo conjunto de modalidades avaliativas instituído na rede: a Prova Rio ${ }^{1}$ e as Avaliações Bimestrais da Rede.

A Prova Rio é uma avaliação anual externa realizada por meio de exames padronizados que seguem, conforme divulgado pela SME/RJ, os moldes da Prova Brasil, ou seja, é composta de testes de múltipla escolha que abrangem as áreas de matemática e língua portuguesa. A SME/RJ instituiu um 
processo de treinamento para a Prova Rio, que envolve, além da preparação dos alunos (por meio da ênfase no ensino dos conteúdos a serem testados nas avaliações e de exercícios que incluem a familiarização com o tipo de teste), a realização de provas ou simulados nas séries que serão avaliadas. Os simulados são testes aplicados também anualmente pela SME/RJ, seguindo os padrões das avaliações externas como treinamento para a Prova Rio e para a Prova Brasil.

As Avaliações Bimestrais da Rede são testes de múltipla escolha de Língua Portuguesa, Matemática e Ciências, aplicados a todas as séries do ensino fundamental. Seus resultados são monitorados pela SME/RJ e compõem a nota média do aluno na escola. Essas avaliações estão articuladas a dois outros instrumentos didáticos introduzidos pela mesma política: os Descritores de Ensino (listas bimestrais de habilidades e conteúdos a serem contemplados nas Avaliações Bimestrais da Rede) e os Cadernos de Apoio Pedagógico (apostilas bimestrais de exercícios das disciplinas avaliadas que visam complementar o trabalho do professor e preparar os alunos para a Avaliação Bimestral da Rede). Esse conjunto de políticas passou a vigorar como resposta e ruptura em relação à política educacional da gestão anterior (2005/2008), que organizava os anos escolares em ciclos e que ficou popularmente conhecida como "aprovação automática", intensificada e estendida a todo o ensino fundamental no último ano daquela gestão municipal.

Quando essa nova "política avaliativa", com todos os seus instrumentos e demandas, chegou ao contexto escolar, alterou significativamente sua rotina. Como os educadores incorporaram esses instrumentos em sua prática? Como lidaram com o desafio de gerenciar tais mudanças? O que cabe à gestão da escola nesse contexto? Para pensar essas questões, busca-se refletir, na próxima seção, sobre a relação entre gestão e eficácia escolar.

\section{GESTÃO ESCOLAR}

Ball (2001, p. 108) considera que, "durante os últimos vinte anos, a gestão tem sido um mecanismo chave tanto na 
reforma política, quanto na reengenharia cultural no setor público [...]. Enquanto os mercados trabalham de fora para dentro, a gestão funciona de dentro para fora”.

Os estudos sobre a eficácia escolar vêm tentando determinar o efeito das experiências vivenciadas na escola (que são particulares e relativas às características da instituição) na aprendizagem dos alunos. Assim, controlando as características iniciais dos alunos (origem socioeconômica, cor/raça, organização familiar, por exemplo), essas pesquisas buscam aferir quais fatores estruturais e organizacionais das escolas estão associados a diferentes resultados acadêmicos entre elas, ou seja, entre escolas que atendem alunos com perfis semelhantes, e o que aquelas que apresentam melhores resultados acadêmicos têm e fazem para alcançá-los.

Sammons (2008, p. 336) levantou onze "características-chave das escolas eficazes", dentre as quais se destacam estrutura da escola, aspectos da gestão, valorização de um ambiente organizado para a aprendizagem e estratégias do professor. Alves e Franco (2008, p. 494) resumem, no caso brasileiro, tais fatores em cinco categorias: recursos escolares, organização e gestão da escola, clima acadêmico, formação e salário docente e ênfase pedagógica. Ambos os trabalhos apontam a gestão escolar como um dos fatores intraescolares que podem influenciar positivamente o desempenho do aluno e a eficácia escolar. Com base na proposição de um modelo conceitual para abordar o processo de aprendizagem em uma perspectiva multidisciplinar, Soares (2007, p. 153) considera que "dentro da escola há dois importantes processos que interagem para a produção do desempenho dos alunos: a gestão escolar e o ensino". De acordo com o autor, a gestão da escola, liderada pelo(a) diretor(a), compreende as tarefas relativas à garantia do funcionamento da instituição "de forma que os recursos nela existentes possam ser usados para atender às necessidades de aprendizagem dos alunos" (SOARES, 2007, p. 153). Isso envolve tarefas rotineiras, como acompanhar e efetivar a assiduidade de alunos e professores, identificar os problemas de aprendizagem e buscar recursos para saná-los, estabelecer contatos com as famílias dos alunos em prol de seu acompanhamento escolar, garantir o 
acesso de alunos e professores aos materiais didáticos necessários para o trabalho escolar, entre outras. Sendo a gestão escolar um dos fatores intraescolares que podem influenciar o desempenho dos estudantes, como seu trabalho é afetado pelas políticas de avaliação e responsabilização em vigor?

A pesquisa de Oliveira (2012a), desenvolvida durante os anos de 2010 e $2011,{ }^{2}$ ressaltou que as determinações das políticas públicas, como as que instituem avaliações externas para acompanhar o trabalho desenvolvido nas escolas, dependem, em sua maioria, da articulação do trabalho da gestão para chegar ao professor e à sala de aula. De acordo com os dados desse estudo, a mediação realizada pela equipe gestora da escola, entre as determinações da SME/RJ e o trabalho dos professores, foi fundamental para o bom andamento da atividade docente. Muitas dúvidas surgiam na organização do calendário de avaliações e no cumprimento das exigências burocráticas e cabia à gestão da escola esclarecer e direcionar o trabalho.

Entre as mudanças provocadas no trabalho dos gestores pela aplicação das avaliações aos alunos da rede pública municipal do Rio de Janeiro, mencionadas anteriormente, o estudo em tela destacou as seguintes: reorganização do calendário e da rotina da escola, alterando horários e definindo salas para a aplicação de provas, horários para esclarecer dúvidas e instruir os professores sobre os instrumentos, prazos e demandas de cada avaliação; monitoramento, publicação e comparação dos resultados dos alunos, propondo estratégias de recuperação para aqueles com dificuldades e atividades de revisão para as questões com grande índice de erro. O estudo mostrou um expressivo impacto no trabalho desenvolvido pela gestão da escola, ressaltando que as entrevistas e as observações realizadas no ambiente investigado enfatizaram a queixa quanto ao excesso de avaliações e a prevalência do trabalho burocrático do gestor, dada a necessidade constante de organização e registro dos dados. Contudo, a equipe gestora incorporou as novas atribuições em sua rotina, buscando desempenhá-las de acordo com o que lhes era determinado e com o compromisso de manter os bons resultados que a escola tradicionalmente atingia antes da política.
2 Trata-se de um estudo baseado num trabalho intenso de mais de um ano de observação do cotidiano escolar, que incluiu, ainda, entrevistas com a equipe de gestão da escola (direção e coordenação pedagógica) e professores. 
Talvez estas sejam mais algumas características de uma gestão comprometida com a eficácia escolar: a capacidade de adaptação às mudanças e a proatividade frente aos desafios. Entretanto, o mesmo estudo mostrou que, muitas vezes, as estratégias da equipe de gestão eram afetadas pela sobrecarga de trabalho e pelas dificuldades para manter a estabilidade e a assiduidade no quadro de funcionários da escola. $\mathrm{Na}$ seção que se segue, propõe-se uma reflexão sobre o impacto das condições de trabalho do diretor na gestão escolar.

\section{CONDIÇÕES DE TRABALHO DA GESTÃO ESCOLAR}

As condições de gestão das redes públicas de ensino e, particularmente, das escolas dependem de insumos que interferem em seu funcionamento, produzindo efeitos nas condições de trabalho e na qualidade do ensino. Contudo, os diretores geralmente têm pouca margem de decisão ou poder para alterar algumas das dimensões da gestão escolar e o quadro frequente de escassez de recursos que afetam seu cotidiano.

Torna-se, assim, imperativo que formuladores de políticas considerem, nos contextos escolares, a disponibilidade e as condições de uso dos recursos relacionados à infraestrutura, ao quadro de pessoal, aos materiais pedagógicos e às dependências físicas que, conforme evidências de pesquisas (GOMES; REGIS, 2012; SOARES; SATYRO, 2008; SOARES et al., 2010; ALVES, 2009; SOARES; TEIXEIRA, 2006), não são distribuídos homogeneamente nas redes de ensino ou entre as escolas.

Nesse sentido, os questionários contextuais da Prova Brasil podem oferecer informações sobre alunos e escolas, em particular sobre as percepções dos agentes escolares professores e diretores - no âmbito das condições de gestão. Essas informações podem ainda ser complementadas pelas percepções dos aplicadores dos exames sobre as condições de infraestrutura do ambiente escolar, identificando problemas estruturais e de manutenção ou uso efetivo de recursos que podem influenciar o desempenho do aluno. Dentre os estudos citados, cabe ressaltar o de Gomes e Regis (2012), 
que se vale dessas informações para discutir sua influência nos resultados escolares na região metropolitana do Rio de Janeiro. Esses aspectos parecem particularmente relevantes quando se trata de implementar políticas de avaliação e de responsabilização pelos resultados, que estabelecem a meritocracia e a bonificação como mecanismos indutores de qualidade.

Dentre os elementos da gestão que podem ser apreendidos nas respostas dos questionários contextuais da Prova Brasil, destacam-se a gestão de pessoal como uma das dimensões que potencialmente afetam o trabalho dos profissionais de educação, o funcionamento das escolas e o desempenho dos alunos (LIMA; ALCÂNTARA; ALMEIDA, 2013). Cabe assinalar que essa dimensão sofre ação limitada dos diretores, em vista da legislação que orienta a organização das redes públicas de ensino, a lotação de funcionários e docentes, bem como o eventual contingenciamento de recursos financeiros e a dotação orçamentária fixada para essa finalidade. Em que pese a centralidade dos diretores e seu papel de liderança na organização do trabalho escolar, suas possibilidades de intervenção são dependentes da política e da ação estatal para atender, por exemplo, a demanda de professores e funcionários das escolas.

No segundo movimento de pesquisa aqui considerado, analisam-se as respostas dos diretores da rede pública municipal de ensino do Rio de Janeiro aos questionários contextuais da Prova Brasil em 2007, 2009 e 2011, como mostram as Tabelas 1 e 2 apresentadas a seguir. 
TABELA 1 - Pessoal Administrativo

\begin{tabular}{l|c|c|c}
\hline $\begin{array}{c}\text { OCORREU NA ESCOLA CARÊNCIA DE } \\
\text { PESSOAL ADMINISTRATIVO }\end{array}$ & $\mathbf{2 0 0 7}$ & $\mathbf{2 0 0 9}$ & $\mathbf{2 0 1 1}$ \\
\hline Não & $41 \%$ & $32 \%$ & $38 \%$ \\
\hline Sim, mas não foi um problema grave & $36 \%$ & $34 \%$ & $38 \%$ \\
\hline Sim, e foi um problema grave & $21 \%$ & $31 \%$ & $19 \%$ \\
\hline Não respondeu & $1 \%$ & $4 \%$ & $4 \%$ \\
\hline Total & $100 \%$ & $100 \%$ & $100 \%$ \\
\hline
\end{tabular}

Nota: Em 2007 a pergunta do questionário contextual teve a seguinte redação: "Prob/ema que ocorreu na escola dificultando o funcionamento: Carência de pessoal administrativo?". Já em 2009 e em 2011, a redação foi: "Ocorreu na escola carência de pessoal administrativo?"

Fonte: Prova Brasil 2007, 2009 e 2011.

Na Tabela 1, as respostas dos diretores em 2009 indicam uma percepção mais aguda da carência de pessoal administrativo naquele ano, que parece corroborar as observações do estudo de caso de Oliveira (2012b) a respeito da sobrecarga de tarefas burocráticas da gestão, sem uma contrapartida de apoio administrativo de acordo com as novas demandas surgidas com as políticas de avaliação da SME/RJ. Ainda que os dados mostrem uma alteração em 2011 quanto à percepção da gravidade do problema, $57 \%$ dos diretores continuam a identificar "carência de pessoal técnico administrativo" como um problema da escola.

TABELA 2 - Pessoal de Apoio Pedagógico

\begin{tabular}{|c|c|c|c|}
\hline $\begin{array}{l}\text { OCORREU NA ESCOLA CARÊNCIA DE } \\
\text { PESSOAL DE APOIO PEDAGÓGICO }\end{array}$ & 2007 & 2009 & 2011 \\
\hline Não & $69 \%$ & $64 \%$ & $71 \%$ \\
\hline Sim, mas não foi um problema grave & $20 \%$ & $17 \%$ & $17 \%$ \\
\hline Sim, e foi um problema grave & $10 \%$ & $16 \%$ & $8 \%$ \\
\hline Não respondeu & $1 \%$ & $4 \%$ & $4 \%$ \\
\hline Total & $100 \%$ & $100 \%$ & $100 \%$ \\
\hline
\end{tabular}

Nota: Em 2007 a pergunta do questionário contextual teve a seguinte redação: "Problema que ocorreu na escola dificultando o funcionamento: Carência de pessoal de apoio pedagógico (coordenador, supervisor, orientador educacional)?". Já em 2009 e em 2011, a redação foi: "Ocorreu na escola carência de pessoal de apoio pedagógico (coordenador, supervisor, orientador educacional)?".

Fonte: Prova Brasil 2007, 2009 e 2011. 
No que se refere ao pessoal de apoio pedagógico, a Tabela 2 registra um crescimento da percepção da carência de coordenadores e outros profissionais de apoio pedagógico em 2009, que se dilui em 2011. Essa alteração positiva da percepção de falta de profissionais também é observada nos dados relativos ao corpo docente e se explica pelo ingresso na rede de cerca de 9.000 profissionais de educação ${ }^{3}$ entre 2009 e 2011 (FUNDAÇÃO JOÃO GOULART, s.d.).

Ainda assim, os dados sinalizam que a sobrecarga de trabalho dos diretores já era acentuada, notadamente diante do volume das atribuições da gestão, ampliado em decorrência da proliferação de programas e projetos educacionais e da interface social da escola na última década. A indução à melhoria da qualidade requer, além de novos conhecimentos técnicos, tempo para planejar, executar despesas, prestar contas, manter reuniões com a comunidade escolar e acompanhar o processo de ensino-aprendizagem desenvolvido pela escola. Desse ponto de vista, a expectativa seria que os diretores, para além da capacidade técnica necessária para conduzir a gestão, estivessem desimpedidos das atribuições burocráticas que podem ser cumpridas por funcionários administrativos, para dedicarem-se aos aspectos políticos da gestão e às questões pedagógicas que afetam a aprendizagem e o desempenho dos alunos.

Cabe ainda ressaltar que, na rede pública do Rio de Janeiro, no caso dos funcionários (merendeiras e serventes), não há concurso público há mais de dez anos e a maioria dos profissionais que atuam na limpeza, na alimentação e

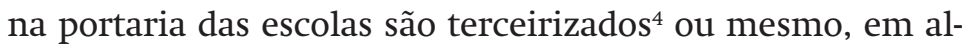
guns casos, voluntários. A precariedade dessas situações e soluções, no entanto, tampouco supre a demanda de serviços administrativos das escolas, como mostram as respostas dos diretores.

\section{A POLÍTICA DE BONIFICAÇÃO NA REDE MUNICIPAL DO RIO DE JANEIRO}

Como já assinalado, a SME/RJ desenvolveu, a partir de 2009, uma política de avaliação articulada a uma política de $\mathbf{3}$ Ingressaram na rede municipal do Rio de Janeiro, por meio de concurso público, no período de 2009 a 2011, 8.612 profissionais, dos quais 2.891 eram professores de educação infantil; 1.801, professores de anos iniciais e 3.920 , professores de anos finais do ensino fundamental, segundo dados da Fundação João Goulart, responsável pelos concursos.

4 Parte da demanda é atendida por meio de contratos com empresas que terceirizam serviços de limpeza e preparo da alimentação escolar. 
5 "Para o melhor acompanhamento do Plano Estratégico de Gestão da Prefeitura foram pactuados Acordos de Resultados como uma ferramenta usada na administração pública para: (i) garantir um maior comprometimento de toda a máquina pública municipal com os resultados da Prefeitura; (ii) institucionalizar uma nova cultura que privilegie o planejamento com metas claras; (iii) motivar a participação dos servidores com um modelo de meritocracia que avalie e premie aqueles que atingirem bons resultados e; (iv) antecipar problemas e apontar soluções através do acompanhamento formal dos resultados obtidos. O que está se propondo é a implementação de um modelo de gestão de desempenho que privilegie o planejamento (metas claras) e a meritocracia como elementos centrais para a melhoria dos serviços prestados à população A implantação bem-sucedida desse modelo de gestão de desempenho garantirá um maior comprometimento de toda a máquina pública municipa com os resultados da prefeitura, aumentando significativamente nossas chances de atingir as metas propostas à sociedade carioca durante o primeiro ano da administração" (RIO DE JANEIRO, 2013) responsabilização e bonificação dos agentes escolares de acordo com os resultados anuais alcançados pelas escolas da rede, considerando as metas estabelecidas pela política nacional e pela própria Secretaria com base nos resultados do Ideb e do IDE-Rio. Nesta seção, apresenta-se essa política, a qual integra o escopo mais amplo da denominada "gestão de resultados" que se constituiu como uma marca de todo o governo municipal no período analisado, formalizada por meio da assinatura anual de um Acordo de Resultados e Termo de Compromisso, que define metas para os gestores (centrais, intermediários e locais) e funcionários dos diferentes órgãos da administração direta e entidades da administração pública indireta da Prefeitura (RIO DE JANEIRO, 2009). ${ }^{5}$

No caso das escolas, as metas são previamente pactuadas mediante o Termo de Compromisso de Desempenho Educacional, assinado pelo diretor de cada unidade. Diretores, professores e funcionários que atingem as metas recebem uma bonificação anual correspondente a um salário extra ou o $14^{\circ}$ salário. Embora o detalhamento do desenho da política tenha sofrido algumas adaptações no período analisado (2009 a 2011), sua análise foge ao escopo do terceiro movimento de pesquisa, integrado neste artigo, que busca identificar eventuais tendências de mudança na gestão pedagógica das escolas a partir da premiação, ou não, dos agentes escolares.

Do ponto de vista da gestão escolar, as consequências das políticas de bonificação pelo resultado parecem integrar a pauta da relação entre os agentes escolares e desafiar a competência pedagógica e política da equipe de gestão na condução das ações com vistas ao alcance das metas definidas pela SME/RJ. Nesse terceiro movimento de investigação, busca-se identificar possíveis tendências de alteração nas práticas dos diretores referentes à gestão pedagógica (atividades de formação continuada, critérios de matrícula e de organização de turmas) que, potencialmente, estariam relacionadas às políticas de avaliação e responsabilização/bonificação. Considera-se a hipótese de que a política de bonificação tensiona as relações na escola, num contexto de gestão já desafiado pela frequente escassez de recursos humanos 
para o apoio administrativo. Desenvolve-se o estudo exploratório ora apresentado tendo em vista as prováveis necessidades de intervenção pedagógica associadas à implementação na rede municipal do Rio de Janeiro das políticas avaliativas e de bonificação a partir de 2009.

Para analisar os efeitos dessa política de bonificação sobre a gestão pedagógica, foram selecionadas as escolas da rede municipal do Rio de Janeiro que participaram das edições de 2009 e 2011 da Prova Brasil, perfazendo um total de 697 unidades. Dessas, 170 não foram premiadas no período e 113 foram premiadas nos dois anos. Esses dois grupos representariam, respectivamente, as escolas que não conseguiram ( $1^{\circ}$ grupo) ou conseguiram ( $2^{\circ}$ grupo) melhorar seus resultados no Ideb e no IDE-Rio até as metas estabelecidas pela SME/ RJ para os anos de 2009 e 2010.

As escolas que atingiram suas metas na Prova Brasil 2009 foram informadas sobre a bonificação em 2010, após a divulgação dos resultados. Portanto, as respostas aos questionários contextuais de 2009 foram registradas antes de elas receberem ou serem informadas de que receberiam qualquer bonificação. Por outro lado, as respostas aos questionários contextuais da Prova Brasil 2011 foram dadas após as escolas receberem (ou não) a premiação referente às metas do Ideb 2009 em 2010 e a premiação referente às metas do IDE-Rio 2010 paga em 2011. Cabe assinalar que se trata, na verdade, de um intervalo ainda pequeno para avaliar alterações de monta em práticas escolares, o que explica o caráter apenas exploratório do estudo desenvolvido.

Foram analisadas as respostas dos diretores aos questionários da Prova Brasil de 2009 e 2011 para esses dois grupos com o objetivo de identificar alterações e/ou continuidades em práticas de gestão pedagógica relacionadas, em maior ou menor medida, a alguns aspectos da gestão mais diretamente associados ao desempenho discente. As Tabelas 3 e 4 apresentam as respostas sobre a oferta de formação continuada aos docentes dessas escolas e a participação destes nas atividades. 
TABELA 3 - Premiação e Promoção de Atividade de Formação Continuada

\begin{tabular}{|c|c|c|c|c|}
\hline \multirow{2}{*}{$\begin{array}{l}\text { PROMOVEU ALGUMA ATIVIDADE DE FORMAÇÃO } \\
\text { CONTINUADA NA ESCOLA }\end{array}$} & \multicolumn{2}{|c|}{ SEM PREMIAÇÃO } & \multicolumn{2}{|c|}{$\begin{array}{l}\text { PREMIADA EM } \\
2009 / 2010 \text { E } 2010 / 2011\end{array}$} \\
\hline & 2009 & 2011 & 2009 & 2011 \\
\hline Sim & $40 \%$ & $55 \%$ & $45 \%$ & $67 \%$ \\
\hline Não & $57 \%$ & $38 \%$ & $48 \%$ & $29 \%$ \\
\hline Não respondeu & $3 \%$ & $7 \%$ & $7 \%$ & $4 \%$ \\
\hline Total & $100 \%$ & $100 \%$ & $100 \%$ & $100 \%$ \\
\hline
\end{tabular}

Nota: Em 2011 esta pergunta do questionário contextual foi levemente modificada, ganhando a seguinte redação: "Você promoveu alguma atividade de formação continuada (atualização, treinamento, capacitação, etc.) nesta escola?".

Fonte: Elaboração das autoras com base nos dados da SME/RJ, 2010; SME/RJ, 2011; Prova Brasil 2009 e 2011.

TABELA 4 - Premiação em 2009 e 2011 e Participação Docente na Formação Continuada

\begin{tabular}{|c|c|c|c|c|}
\hline \multirow{2}{*}{$\begin{array}{l}\text { PROPORÇÃO DE DOCENTES DA } \\
\text { ESCOLA QUE PARTICIPOU DAS } \\
\text { ATIVIDADES DE FORMAÇÃO } \\
\text { CONTINUADA PROMOVIDAS POR } \\
\text { VOCÊ NOS DOIS ÚLTIMOS ANOS }\end{array}$} & \multicolumn{2}{|c|}{ SEM PREMIAÇÃO } & \multicolumn{2}{|c|}{$\begin{array}{c}\text { PREMIADA EM 2009/2010 E } \\
2010 / 2011\end{array}$} \\
\hline & 2009 & 2011 & 2009 & 2011 \\
\hline Menos de $10 \%$ & $3 \%$ & O\% & $2 \%$ & $1 \%$ \\
\hline Entre $11 \%$ e $30 \%$ & $2 \%$ & $4 \%$ & $2 \%$ & $2 \%$ \\
\hline Entre $31 \%$ e $50 \%$ & $6 \%$ & $7 \%$ & $2 \%$ & $2 \%$ \\
\hline Mais de $51 \%$ & $37 \%$ & $44 \%$ & $43 \%$ & $63 \%$ \\
\hline Não sabe & $2 \%$ & $1 \%$ & $2 \%$ & O\% \\
\hline Não respondeu & $51 \%$ & $44 \%$ & $50 \%$ & $33 \%$ \\
\hline Total & $100 \%$ & $100 \%$ & $100 \%$ & $100 \%$ \\
\hline
\end{tabular}

Nota: Em 2011 a pergunta do questionário contextual foi levemente modificada, ganhando a seguinte redação: "Qual foi a proporção de docentes da sua escola que participou das atividades de formação continuada promovidas por você nos últimos dois anos?".

Fonte: Elaboração das autoras com base nos dados da SME/RJ, 2010; SME/RJ, 2011; Prova Brasil 2009 e 2011.

De maneira geral, a oferta de formação continuada nas escolas parece ter crescido, em particular nas unidades premiadas nos dois anos. A Tabela 4 mostra que a proporção de docentes que participa das atividades de formação continuada também aumentou em ambas as situações, mas ocorreu de forma mais acentuada nas escolas premiadas. Pode-se levantar a hipótese de que a articulação das políticas de avaliação e bonificação tenha incrementado tanto o interesse dos 
professores em participar de atividades de formação, como dos gestores escolares em propiciá-las a sua equipe, como estratégia de consolidação ou garantia da continuidade do sucesso expresso no alcance das metas.

Outro aspecto afeto à gestão da escola são os critérios usados para admissão de alunos na época da matrícula (ou fora dela). Apesar do sistema informatizado de matrícula adotado pela SME/RJ, ${ }^{6}$ que supostamente uniformizaria esses processos no âmbito da rede municipal, parece haver uma alteração nesse período, como indica a Tabela 5.

TABELA 5 - Critério de Admissão de Alunos

\begin{tabular}{|c|c|c|c|c|}
\hline \multirow{2}{*}{$\begin{array}{c}\text { CRITÉRIO UTILIZADO PARA } \\
\text { A ADMISSÃO DE ALUNOS NA } \\
\text { ESCOLA }\end{array}$} & \multicolumn{2}{|c|}{ SEM PREMIAÇÃO } & \multicolumn{2}{|c|}{$\begin{array}{l}\text { PREMIADA EM } \\
2009 / 2010 \mathrm{E} \\
2010 / 2011\end{array}$} \\
\hline & 2009 & 2011 & 2009 & 2011 \\
\hline Prova de seleção* & - & $0 \%$ & - & $0 \%$ \\
\hline Sorteio* & - & $1 \%$ & - & O\% \\
\hline Local de moradia & $3 \%$ & $4 \%$ & $45 \%$ & $2 \%$ \\
\hline Prioridade por ordem de chegada & $31 \%$ & $14 \%$ & $0 \%$ & $23 \%$ \\
\hline Outro critério & $17 \%$ & $33 \%$ & $20 \%$ & $45 \%$ \\
\hline Não existe critério preestabelecido & $47 \%$ & $42 \%$ & $32 \%$ & $27 \%$ \\
\hline Não respondeu & $3 \%$ & $6 \%$ & $4 \%$ & $3 \%$ \\
\hline Total & $100 \%$ & $100 \%$ & $100 \%$ & $100 \%$ \\
\hline
\end{tabular}

Nota (*): Alternativas de resposta que só foram disponibilizadas no questionário de 2011.

Fonte: Elaboração das autoras com base nos dados da SME/RJ, 2010; SME/RJ, 2011; Prova Brasil 2009 e 2011.

Observam-se diferenças interessantes entre os critérios assinalados pelos diretores dos dois grupos de escolas nos anos analisados. Os diretores das escolas não premiadas afirmam majoritariamente não possuir critérios preestabelecidos e, secundariamente, passam da aparente preferência pelo critério "Prioridade por ordem de chegada" em 2009 para "Outro critério" em 2011.

Por outro lado, os diretores de escolas premiadas parecem estar no movimento de mudança em direção à adoção de "Outro critério" (de $20 \%$ para $45 \%$ ). Ainda nessas escolas, o critério que praticamente deixa de ser considerado, segundo
6 As matrículas são efetuadas em duas etapas na rede pública municipal do Rio. A primeira corresponde à pré-matrícula e é realizada pela internet em um site exclusivo para essa finalidade. Nesse momento, são efetuadas pré-matrículas iniciais, transferências internas (dentro da rede) e externas (de outras redes para a rede do Rio). No ato da inscrição, é necessário indicar entre três e cinco escolas de interesse. Após a confirmação da inscrição, por SMS, e-mail ou carta, é preciso comparecer à escola com a documentação solicitada para confirmar a matrícula no período designado pela SME. Para aqueles que perderam a primeira etapa, são oferecidas vagas remanescentes em um momento posterior. Esse mecanismo de matrícula, adotado desde 2010, estabeleceu outra relação entre a escola e as famílias. Anteriormente, a matrícula ocorria presencialmente, em uma única etapa, em polos de matrícula, na presença de diretores de escolas que integravam uma determinada região do bairro e de Coordenadoria Regional de Educação, alocados numa escola de fácil acesso para a população. O que determinava a matrícula, até então, era, presumivelmente, a ordem de chegada. 
as respostas de seus diretores, é o de proximidade da moradia dos alunos e famílias, enquanto que o ingresso por ordem de chegada passa a ser uma opção comum e atinge $23 \%$. Esses resultados parecem reforçar a ideia de que a premiação - divulgada pela mídia e junto às famílias - tenha influído positivamente na percepção externa dessas escolas, que passam a ser mais atrativas, em especial para famílias bem informadas, o que já indica a posse de certo capital social e informacional.

Caberia questionar se o aumento expressivo da menção a "outro critério" poderia registrar a prevalência de uma maior seletividade não explícita, possivelmente contribuindo para a desigualdade de oportunidades educacionais analisadas por Costa e Koslinski (2011, p. 252), entre outros, na perspectiva de um "quase-mercado" educacional.

A Tabela 6, apresentada a seguir, mostra a percepção dos gestores escolares sobre a oferta de vagas em sua escola.

TABELA 6 - Oferta de vagas

\begin{tabular}{|c|c|c|c|c|}
\hline \multirow{2}{*}{$\begin{array}{c}\text { SITUAÇÃO DA OFERTA DE VAGAS NA ESCOLA } \\
\text { NESTE ANO }\end{array}$} & \multicolumn{2}{|c|}{ SEM PREMIAÇÃO } & \multicolumn{2}{|c|}{$\begin{array}{l}\text { PREMIADA EM } \\
2009 / 2010 \mathrm{E} \\
2010 / 2011\end{array}$} \\
\hline & 2009 & 2011 & 2009 & 2011 \\
\hline Após a matrícula, a escola ainda tinha vagas disponiveis & $42 \%$ & $41 \%$ & $37 \%$ & $33 \%$ \\
\hline A procura preencheu todas as vagas disponíveis & $15 \%$ & $21 \%$ & $20 \%$ & $12 \%$ \\
\hline A procura foi maior que as vagas oferecidas & $27 \%$ & $22 \%$ & $29 \%$ & $33 \%$ \\
\hline A procura por vagas superou em muito a oferta & $11 \%$ & $13 \%$ & $11 \%$ & $20 \%$ \\
\hline Não respondeu & $5 \%$ & $3 \%$ & $3 \%$ & $2 \%$ \\
\hline Total & $100 \%$ & $100 \%$ & $100 \%$ & $100 \%$ \\
\hline
\end{tabular}

Fonte: Elaboração das autoras com base nos dados da SME/RJ, 2010; SME/RJ, 2011 ; Prova Brasil 2009 e 2011.

Nos dois anos analisados, a oferta de vagas é maior do que a demanda em mais de $40 \%$ das escolas não premiadas, um sinal de baixa procura das famílias por essas escolas, o que pode ser interpretado como expressão também de uma percepção negativa ou não muito positiva da qualidade de seus serviços educacionais. É interessante observar que, 
passados dois anos da implantação das políticas e da crescente divulgação de rankings com os resultados, bem como de sua socialização também com as famílias, parece ter havido pequenas alterações na demanda por vagas nessas escolas.

Já nas escolas premiadas, a proporção dos diretores que afirma que a demanda foi maior do que a oferta ("foi maior" e/ou "superou em muito") subiu 13 pontos percentuais (de $40 \%$ para 53\%). Portanto, seja por influência direta da divulgação dos resultados e premiações, seja pela circulação dessas e outras informações relacionadas ao trabalho dessas escolas, parece tender a crescer uma seletividade maior por parte das famílias, dando preferência às escolas cujos resultados atingiram as metas estabelecidas pela SME/RJ.

Finalmente, a Tabela 7, apresentada a seguir, registra as respostas dos diretores dos dois grupos de escolas sobre os critérios utilizados na formação das turmas - tema de expressiva relevância na agenda da gestão pedagógica, que tem sido apontado pelas pesquisas nacionais e internacionais no campo da sociologia da educação como uma das ferramentas da gestão escolar que podem influenciar os resultados do alunado (ALVES; FRANCO, 2008).

TABELA 7 - Critérios usados na formação de turmas

\begin{tabular}{|c|c|c|c|c|}
\hline \multirow{2}{*}{$\begin{array}{l}\text { CRITÉRIO UTILIZADO PARA A FORMAÇÃO } \\
\text { DAS TURMAS NA ESCOLA }\end{array}$} & \multicolumn{2}{|c|}{ SEM PREMIAÇÃO } & \multicolumn{2}{|c|}{$\begin{array}{l}\text { PREMIADA EM 2009/2010 E } \\
2010 / 2011\end{array}$} \\
\hline & 2009 & 2011 & 2009 & 2011 \\
\hline Homogeneidade quanto à idade & $79 \%$ & $72 \%$ & $78 \%$ & $74 \%$ \\
\hline $\begin{array}{l}\text { Homogeneidade quanto ao rendimento } \\
\text { escolar }\end{array}$ & $3 \%$ & $2 \%$ & $3 \%$ & $5 \%$ \\
\hline Heterogeneidade quanto à idade & $1 \%$ & $4 \%$ & $2 \%$ & $1 \%$ \\
\hline Heterogeneidade quanto ao rendimento & $7 \%$ & $12 \%$ & $13 \%$ & $15 \%$ \\
\hline Não houve critério & $4 \%$ & $6 \%$ & $1 \%$ & $4 \%$ \\
\hline Não respondeu & $6 \%$ & $3 \%$ & $4 \%$ & $2 \%$ \\
\hline Total & $100 \%$ & $100 \%$ & $100 \%$ & $100 \%$ \\
\hline
\end{tabular}

Fonte: Elaboração das autoras com base nos dados da SME/RJ, 2010; SME/RJ, 2011 ; Prova Brasil 2009 e 2011. 
Em 2009 e 2011, não foram observadas alterações relevantes nos processos de formação das turmas de alunos nos dois grupos de escolas. Mais de 70\% dos diretores dos dois grupos, nos dois anos, assinalaram que o critério utilizado nas escolas que dirigem é o de "homogeneidade quanto à idade”. Ainda assim, nota-se uma pequena queda dessa alternativa no período para os dois grupos, dando lugar, aparentemente, a critérios que valorizam também o rendimento escolar. Vale ressaltar que o ano de 2009 marca o fim da organização escolar por ciclos no município do Rio de Janeiro.

Finalmente, a oferta de programa de apoio ou reforço de aprendizagem para os alunos é declarada como existente e regular por mais de $90 \%$ dos diretores dos dois grupos. Observa-se, porém, uma pequena elevação desse percentual entre 2009 e 2011. Esse aumento poderia ser explicado pela adoção pela SME/RJ de uma política de incentivo ao estágio remunerado de universitários para o atendimento às crianças com dificuldade de aprendizagem na escola.

A breve incursão exploratória realizada nos dados dos questionários contextuais da Prova Brasil 2009 e 2011 desses dois conjuntos de escolas, consecutivamente premiadas (ou não) pelo Prêmio Anual de Desempenho que constitui a política de bonificação da SME/RJ, mostrou alguns traços indicativos de tendências de alteração nas práticas de gestão pedagógica, mais acentuados no grupo de escolas premiadas. Esses indícios, embora não se mostrem em geral estatisticamente significativos, apontam para o interesse no acompanhamento desses processos de implementação de políticas e para a avaliação periódica de suas consequências no nível das escolas e de sua gestão, que merecem ser aprofundados em novas pesquisas.

\section{CONSIDERAÇÕES FINAIS}

Este artigo apresentou três movimentos complementares e independentes de investigação sobre alguns dos efeitos das políticas de avaliação e responsabilização adotadas desde 2009 na rede municipal de ensino do Rio de Janeiro. Priorizou-se, nos três relatos de pesquisa, a discussão sobre as 
demandas e desafios da gestão escolar frente às estratégias de avaliação externa e às políticas de responsabilização adotadas pela rede municipal do Rio de Janeiro.

Os três trabalhos ora integrados apresentam alguns dos desafios e tensões cada vez mais presentes na pauta da gestão escolar, alçando ao centro da cena as responsabilidades e as opções pedagógicas estratégicas dos gestores escolares, além das limitações administrativas e político-legais de sua intervenção.

O estudo de caso de Oliveira (2012b) mostra que o excesso de avaliações e os controles a elas relacionados sobrecarregam a gestão, configurando uma nova burocracia na rotina escolar. No caso do município do Rio de Janeiro, além das demandas da aplicação das avaliações nacionais, da Prova Rio e das Avaliações Bimestrais, a equipe de gestão da escola passa a controlar e reportar à SME as notas dos alunos nas avaliações bimestrais a que são também submetidos. Além desse trabalho extra, o papel mediador da equipe de gestão entre a SME/RJ e os professores se acentua e tende a tornar-se um fator determinante para a sustentação do foco na aprendizagem do aluno, que poderá ser também reforçado pela política de bonificação na medida de sua eficácia.

Restaria avaliar como essas demandas têm sido incorporadas por coordenadores e diretores nas escolas e acomodadas em suas condições de trabalho. No que tange à equipe de trabalho disponível na escola, os dados apresentados no segundo estudo denunciam a insuficiência de pessoal administrativo em parte das escolas da rede. A manutenção da precariedade da estrutura de pessoal de apoio administrativo nas escolas torna ainda mais complexo o trabalho da equipe gestora, pressionada a responder pelos resultados alcançados por seus alunos nos testes em larga escala. Em que pese a alteração para melhor do quadro docente, possibilitada pelo número expressivo de concursos públicos para lotação no cargo de professores, realizados no período 2009/2011, conforme assinalado, caberia indagar sobre sua integração efetiva ao trabalho das escolas no âmbito das políticas de avaliação e responsabilização vigentes. 
7 WILLMOTT, H. Strength is ignorance; slavery is freedom: managing culture in modern Organizations. Journal of Management Studies, v. 30, n. 4 p. $215-252,1993$

Novas tensões são trazidas para as relações entre professores e equipe de gestão. Nesse contexto em que os resultados acadêmicos dos alunos são medida para a distribuição de prêmios e conferem visibilidade para a escola, corre-se o risco de que os profissionais se sintam pressionados a apresentarem resultados satisfatórios. Esse sentimento também é verdadeiro nas relações entre os professores (especialmente nas séries avaliadas) e seus coordenadores e diretores, considerando as expectativas em relação a seu trabalho. A disputa por melhores resultados muda a estrutura das relações pessoais, como sugere Wilmmott (1993, p. $222^{7}$ apud BALL, 2001, p. 107): “exige-se dos empregados, individual e coletivamente, que simultaneamente reconheçam e se responsabilizem pela relação entre a segurança do seu posto de trabalho e a sua contribuição para a competitividade dos bens e dos serviços que produzem".

Os dados levantados sobre os diretores das escolas premiadas ou não premiadas pela política de bonificação da SME/RJ revelaram algumas alterações nas respostas desses profissionais no período observado (2009-2011), o que parece indicar uma maior preocupação ou foco nos resultados alcançados por sua escola, expressa, por exemplo, no crescimento da oferta de atividades de formação para os docentes. Houve uma alteração significativa nos percentuais referentes à forma de ingresso do aluno na escola, especialmente nas unidades premiadas. Tal alteração, reduzindo a matrícula por "local de moradia" e aumentando a matrícula por "outro critério", poderia expressar um procedimento de seletividade de alunos, derivado da crescente demanda pelas escolas premiadas. A provisoriedade e o caráter exploratório dos resultados dos levantamentos que constituem o terceiro movimento de investigação apresentado neste artigo apontam a necessidade de seu aprofundamento futuro, sugerindo pistas instigantes para novas pesquisas.

Ainda que a título de conclusão provisória, pode-se inferir das análises apresentadas a necessidade de preparação destes profissionais - diretores e coordenadores escolares para lidar com as demandas colocadas para a gestão escolar que passam a integrar seu cotidiano na última década. Entre elas estão a capacidade de leitura e interpretação de índices e resultados educacionais; a necessidade permanente 
de intermediação entre os órgãos centrais e os profissionais da escola - especialmente os professores -; a interpretação das demandas oriundas das políticas avaliativas a fim de que possam ser utilizadas também como ferramentas de gestão e planejamento pedagógico; a manutenção de um clima escolar favorável, gerenciando as tensões que passam a surgir nas relações escolares em virtude das cobranças de resultados. Acredita-se que tais demandas devam ocupar um espaço cada vez mais relevante e estratégico tanto na pauta do campo acadêmico como no terreno da formulação, implementação e avaliação das políticas públicas de educação.

\section{REFERÊNCIAS}

ALVES, Fátima Cristina. Mapeamento das políticas de escolha de diretores da escola e de avaliação na rede pública das capitais brasileiras. Revista Brasileira de Estudos Pedagógicos, Brasília, v. 90, n. 224, p. 71-86, jan./abr. 2009.

ALVES, Maria Teresa G.; FRANCO, Creso. A pesquisa em eficácia escolar no Brasil: evidências sobre o efeito das escolas e fatores associados à eficácia escolar. In: BROOKE, Nigel; SOARES, José Francisco (Org.). Pesquisa em eficácia escolar: origem e trajetórias. Belo Horizonte: Editora UFMG, 2008.

ALVES, Maria Teresa G.; SOARES, José Francisco. Efeito-escola e estratificação escolar: o impacto da composição de turmas por nível de habilidade dos alunos. Educação em Revista, Belo Horizonte, v. 45, p. 25-58, 2007.

ANDRADE, Eduardo de C. School Accountability no Brasil: experiências e dificuldades. Revista de Economia Política, v. 28, n. 3, p. 443-453, jul./set. 2008. Disponível em: <http://www.scielo.br/pdf/rep/v28n3/a05v28n3 > . Acesso em: 25 nov. 2011.

BALL, Stephen J. Diretrizes políticas globais e relações políticas locais em educação. Currículo Sem Fronteiras, v. 1, n. 2, p. 99-116, jul./dez. 2001. Disponível em: <http://www.curriculosemfronteiras.org/vol1iss2articles/ball. pdf > . Acesso em: 12 maio 2010.

BRASIL. Constituição Federal, 1988. Disponível em: <http://www.planalto. gov.br>. Acesso em: 12 jun. 2013.

Decreto n. 6.094, de 24 de abril de 2007. Dispõe sobre a implementação do Plano de Metas Compromisso Todos pela Educação, pela União Federal, em regime de colaboração com Municípios, Distrito Federal e Estados, e a participação das famílias e da comunidade, mediante programas e ações de assistência técnica e financeira, visando a mobilização social pela melhoria da qualidade da educação básica. Brasília, DF, 2007. Disponível em: < http:// www.planalto.gov.br/ccivil_03/_ato2007-2010/2007/decreto/d6094.htm>.

Acesso em: 2 dez. 2013. 
. Lei de Diretrizes e Bases da Educação Nacional, Lei 9.394/96. Brasília, DF, 1996. Disponível em: <http://www.planalto.gov.br/ccivil_03/leis/19394.htm>. Acesso em 10 jun. 2013.

BRASIL. Ministério da Educação. Instituto Nacional de Estudos e Pesquisas Educacionais Anísio Teixeira. Microdados Prova Brasil 2007. Mídia eletrônica. Brasília, DF, 2007. Disponível em: <http://portal.inep.gov.br/basicalevantamentos-acessar>. Acesso em: 10 fev. 2014.

Microdados Prova Brasil 2009. Mídia eletrônica. Brasília, DF, 2009. Disponível em: <http://portal.inep.gov.br/basica-levantamentos-acessar>. Acesso em: 10 fev. 2014.

Microdados Prova Brasil 2011. Mídia eletrônica. Brasília, DF, 2011. Disponível em: <http://portal.inep.gov.br/basica-levantamentos-acessar>. Acesso em: 10 fev. 2014.

BROOKE, Nigel. Responsabilização educacional no Brasil. Sísifo, Revista Iberoamericana de Evaluación Educativa, v. 1, n. 1., p. 94-109, 2008. Disponível em: <http://www.rinace.net/riee/numeros/vol1-num1/art7_port.html>. Acesso em: 20 out. 2012.

COSTA, Marcio da; KOSLINSKI, Mariane C. Quase-mercado oculto: disputa por escolas "comuns" no Rio de Janeiro. Cadernos de Pesquisa, São Paulo, v. 41, n. 142, jan./abr. 2011.

FERNANDES, Reynaldo; GREMAUD, Amaury. Qualidade da educação: avaliação, indicadores e meta. In: VELOSO, Fernando et al. (Org.). Educação básica no Brasil: construindo o país do futuro. Rio de Janeiro: Elsevier, 2009. p. 213-238. Disponível em: <www.cps.fgv.br/ibrecps/rede/seminario/ reynaldo_paper.pdf>. Acesso em: 3 set. 2012.

FUNDAÇÃO JOÃO GOULART. Administração, concursos e cursos. Disponível em: $<$ http://concursos.rio.rj.gov.br/indexportal.htm>. Acesso em: 16 jul. 2014.

GOMES, Adailda; REGIS, André. Desempenho e infraestrutura: mapeamento das escolas públicas da região metropolitana do Rio de Janeiro. In: CONGRESSO IBERO-AMERICANO DE POLÍTICA E ADMINISTRAÇÃO DA EDUCAÇÃO, 3., 2012, Zaragoza, Espanha. Anais... Zaragoza, Espanha: Anpae, 2012. (Série Cadernos Anpae, v. 15). Disponível em: <http://www.anpae.org.br/ iberoamericano2012/Trabalhos/AdaildaGomesDeOliveira_res_int_GT1.pdf > . Acesso em: 5 out. 2013.

LIMA, Maria de Fátima de M.; ALCÂNTARA, Guilherme de; ALMEIDA, Mônica A. de O. O que potencialmente afeta a gestão escolar? Percepções de diretores de duas redes públicas de ensino do estado do Rio de Janeiro. In: REUNIÃO NACIONAL DA ANPED, 36., 2013, Goiânia. Anais... Sistema Nacional de Educação e Participação Popular: desafios para as políticas educacionais. Goiânia: Anped, 2013.

OLIVEIRA, Ana Cristina P. Política pública e prática docente: quando e como dialogam no espaço escolar: a experiência de uma escola do Rio de Janeiro. 2012. 205 f. Dissertação (Mestrado em Educação) - Pontifícia Universidade Católica do Rio de Janeiro, Departamento de Educação, Rio de Janeiro, 2012a. 
Política pública e gestão escolar: um estudo de caso no Rio de Janeiro. In: CONGRESSO IBERO-AMERICANO DE POLÍTICA E ADMINISTRAÇÃO DA EDUCAÇÃ̃O, 3., 2012, Zaragoza. Cadernos Anpae... Timbaúba: Anpae, 2012b.

RIO DE JANEIRO (Município). Secretaria Municipal da Casa Civil. Acordo de Resultados. Disponível em: <http://www.rio.rj.gov.br/web/cvl/ exibeconteudo?id=1820527>. Acesso em: 25 jul. 2014.

Acordo de Resultados. 24 jun. 2013. Disponível em: <http://www.rio. rj.gov.br/web/cvl/acordo-de-resultados>. Acesso em: 25 jul. 2014.

RIO DE JANEIRO (Município). Secretaria Municipal de Educação. Prefeito e Secretária de Educação anunciam as escolas que receberão o Prêmio Anual de Desempenho. 2010. Disponível em: <http://www.rio.rj.gov.br/web/sme/ exibeconteudo?id=1011528>. Acesso em: 30 nov. 2013.

. Secretaria de Educação anuncia os resultados do IDE-Rio 2010. 2011. Disponível em: <http://www.rio.rj.gov.br/web/sme/ exibeconteudo?id=1772816>. Acesso em 30 nov. 2013.

SAMMONS, Pam. As características-chave das escolas eficazes. In: BROOKE, Nigel; SOARES, José Francisco (Org.). Pesquisa em eficácia escolar: origem e trajetórias. Belo Horizonte: Editora UFMG, 2008.

SOARES, José Francisco. Melhora do desempenho cognitivo dos alunos do ensino fundamental. Cadernos de Pesquisa, v. 37, n. 130, p. 135-160, jan./abr. 2007.

SOARES, Sergey; SÁTYRO, Natália. 0 impacto da infra-estrutura escolar na taxa de distorção idade-série das escolas brasileiras de ensino fundamental - 1998 a 2005. Rio de Janeiro: Ipea, maio 2008.

SOARES, Tufi M.; TEIXEIRA, Lúcia Helena G. Efeito do perfil do diretor na gestão escolar sobre a proficiência do aluno. Estudos em Avaliação Educacional, São Paulo, v. 17, n. 34, maio/ago. 2006.

SOARES, Tufi M. et al. A expectativa do professor e o desempenho dos alunos. Psicologia: Teoria e Pesquisa, Brasília, v. 26, n. 1, p. 157-170, jan./mar. 2010.

UNIVERSIDADE FEDERAL DE MINAS GERAIS. Faculdade de Educação. GAME. A avaliação externa como instrumento da gestão educacional nos estados: relatório final. Fundação Victor Civita, ago. 2011.

CYNTHIA PAES DE CARVALHO

Doutora em Educação pela Pontifícia Universidade

Católica do Rio de Janeiro (PUC-Rio). Professora adjunta do

Departamento de Educação da PUC-Rio, Rio de Janeiro, Rio de Janeiro, Brasil

cynthiapaesdecarvalho@puc-rio.br 
ANA CRISTINA PRADO DE OLIVEIRA

Doutoranda do Programa de Pós-Graduação em Educação da Pontifícia Universidade Católica do Rio de Janeiro (PUC-Rio), Rio de Janeiro, Rio de Janeiro, Brasil ana.prado.oliveira@gmail.com

\section{MARIA DE FÁTIMA MAGALHÃES DE LIMA}

Doutoranda do Programa de Pós-Graduação em Educação da Pontifícia Universidade Católica do Rio de Janeiro (PUC-Rio). Professora da Secretaria Municipal de Educação do Rio de Janeiro (SME/RJ), Rio de Janeiro, Rio de Janeiro, Brasil fatima_mlima@superig.com.br 
